\title{
FEA-ANALYSIS OF SHAFT AND SUPPORTS DEFORMATIONS FOR HUGE PRECISE LATHE. STATICS AND RESONANCES
}

DOI 10.2478/ntpe-2018-0042

\author{
Dr. Stanislau Dounar \\ Dr. Alexandre Lakimovitch \\ Dr. Andrei Ausiyevich \\ Belarusian National Technical University, Belarus \\ Dr. Andrzej Jakubowski \\ Maritime University of Szczecin, Poland
}

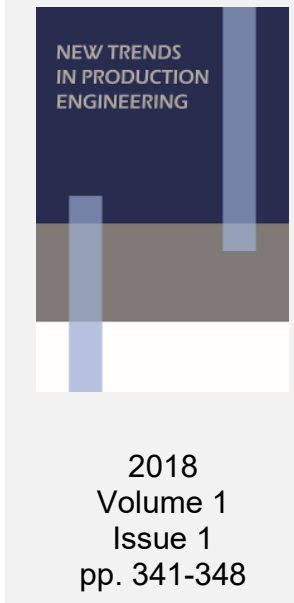

\begin{abstract}
Load bearing system simulation is provided for a huge lathe to be renovated. Static and modal analyses are done by FEM. Focus was centerline rising, needed for larger rotor shaft machining. Forces between shaft and three supports were applied. Shaft static stiffness is lowered at 1.15 times only for 600 $\mathrm{mm}$ centerline rising. Supports have lost its rigidity at 1.42 times. Concrete pouring into bed cavities is recommended for supports flexibility limitation such as tailstock reinforcement. Robustness of bottom resonances is revealed both for rotor shaft $(14.5-18.2 \mathrm{~Hz})$ and supports $(42.7-55.4 \mathrm{~Hz})$. Centerline rising is allowed on $300 \mathrm{~mm}$ at least. It gives possibility to machine extremely large (up to $ø 2750 \mathrm{~mm}$ ) shafts.
\end{abstract}

Keywords: lathe, FEA, rotor, centerline, resonance

\section{INTRODUCTION}

Present work concerns to renovation of huge lathe, machining rotor shafts for shipbuilding and energy branch (generators and turbines mostly). Lathe is aged approved precise machine tool of KZTS brand (Ukraine). Aim of renovation - to increase maximal machined diameter of shaft from $\varnothing 2150$ to $\varnothing 2750 \mathrm{~mm}$ (at least). It may be reachable by centerline rising procedure (CRP). Shaft should be rotated at higher position above bed $(300 \mathrm{~mm}$ up). It will raise maximal shaft diameter at $600 \mathrm{~mm}$. Possibility to turn and mill largest rotor shafts will be reached.

Renovation is worthwhile only if precision will be preserved $( \pm 10 \mu \mathrm{m}$ on diameter). It is hard condition to lathe staying more affective to cutting forces (Wu et al., 2015). Changes statics and dynamics were simulated by FEA technics (Zienkiewicz and Taylor, 2000). Present work is limited to static deformations and resonances of "growing" lathe. Harmonic excitations and will be explored in the next work.

\section{LATHE TO BE RENOVATED AND ITS LOADING}

Fig. $1 \mathrm{a}$, b shows typical shaft $S h$ to be machined. It has length $8.3 \mathrm{~m}$, weight 64.5 ton (in assembled state) and maximal core diameter $\varnothing 1200 \mathrm{~mm}$. Rotor $R t(\varnothing 2250 \mathrm{~mm})$, radial bearing $R b$ and axial bearing $A b$ are fixed on the shaft. Shaft assembly is held for precision cutting by chuck $\mathrm{Ch}$ from the forward and by quill of tail stock TS from the rear. Chuck transmits torque from the spindle $S p$, mounted in headstock HS. Axes of spindle, shaft and tailstock are concurred. It is just lathe centerline.

Headstock and tailstock are allocated upon bed $B d$. Guideways $G 1-G 4$ are designed for supports $S 1, S 2, S 3$, lunette $L$ and tailstock moving. Each support is carrying one tool at least $(t 1, t 2, t 3)$. Cutting tools are installed on the support top. Lunette with four basing pins creates the additional rest for shaft.

Bed is the hollow iron casting. It cavities can be filled with concrete (polymer concrete) Conc (Simon et al., 2012). Foots Ft are allocated beneath bed. Full mass of lathe (Fig. 1) reaches 164 ton for length $15.9 \mathrm{~m}$ (max height $3.35 \mathrm{~m}$ ). 


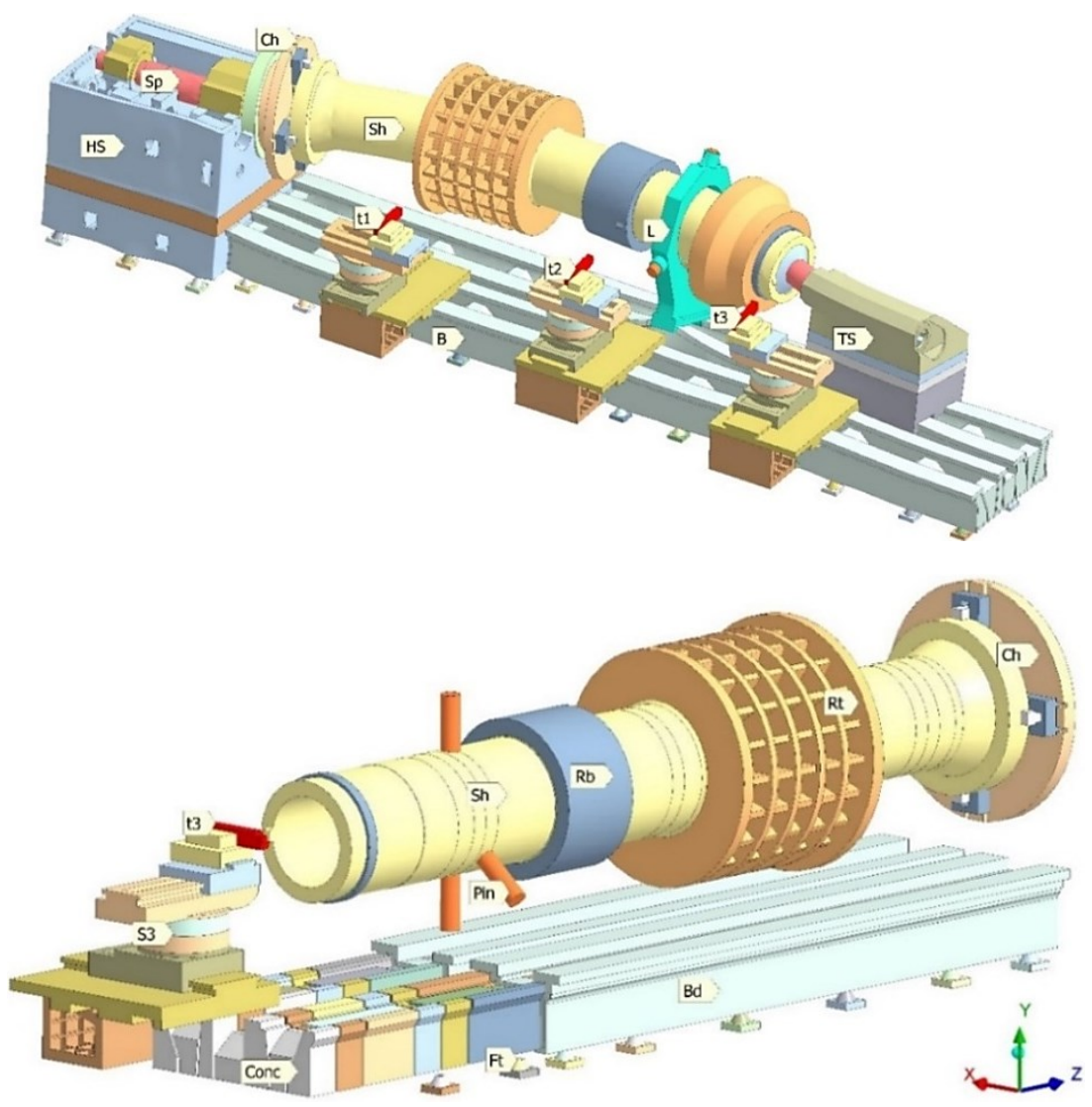

a)

b)

Fig. 1. Huge lathe (RHL state) with large rotor shaft to be machined at the different angles: a - eigenmode MR1 $(18.24 \mathrm{~Hz})$ excitation; $b$ - some structural parts hided

Cutting precision is threatened mainly by insufficient rigidity (or stiffness - reverse terms are flexibility or pliability) (Haddag et al., 2016). It is possible during centerline rising of lathe. New iron inserts (pointed out by S1, S2, S3 markers on Fig. 2) should be placed into supports for its elevation. Similar, inserts A, B are needed for lifting both headstock HS and tailstock TS. As static rigidity, so dynamic one have to be forecasted before renovation. Dynamic stiffness may falls drastically due to resonances.

FEA simulation should be provided before renovation. Lathe would acquire two additional features during renovation besides centerline lifting. At first, there will be up three supports on the guides instead one. As Fig. 1 shows, support $S 1$ is assigned to just rotor $R t$ machining, $S 2$ is for radial bearing $R b$ and $S 3$ - for axial bearing $A b$ and shaft $S h$ rear end. Secondly, not only turning but milling may be provided. Milling head on the support may generate additional harmonic excitations.

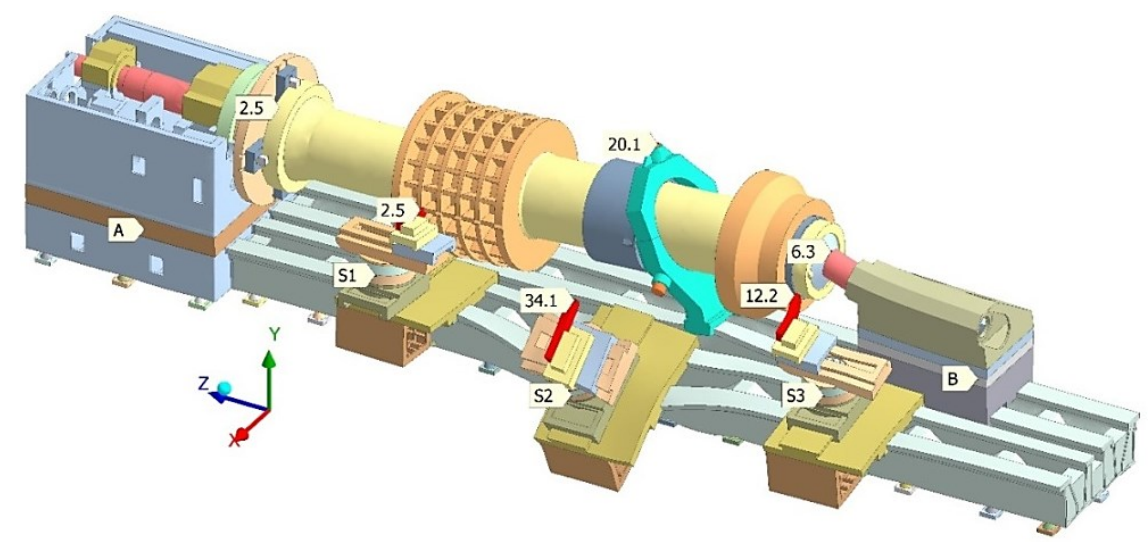

Fig. 2. Total displacements $(\mu \mathrm{m})$ on different lathe structural parts at the middle support $S 2$ resonance accordingly eigenmode $M S 1 b(60.59 \mathrm{~Hz})$ 
Radial direction $X$ has priority for precision. Any deformations along $X$ in double scale affect accuracy of diameter dimensions at rotor shaft. That dimensions are most important for machining. Axial dimensions $(Z)$ have much more wider allowances. Vertical deformations $(Y)$ are tangential and not critical to precision.

Will set three pairs of reference points (Fig. 3). Points $t 1, t 2, t 3$ will be attached to vertexes of cutting tools on three supports. Points $r 1, r 2, r 3$ are tied with cutting zones on the shaft assembly (on rotor, bearing and shaft butt respectively). Points coincide in undeformed case by pairs ( $t 1$ and $r 1$, e.g.).

Supports and shaft are disengaged on Fig. 3 by joined action of three twin forces. Twin force mean (Cao et al., 2011; Vasilevich et al., 2016) pair of equal but opposite directed forces. One force is applied to tool and other one - to cutting zone. For present work twin forces go radially along $X$ and are equal to $1 \mathrm{kN}$ for each. Force on the tool in reference point $t 3$ is marked as $F_{3}^{t}$. Cutting zone force exerts on the reference point $r 3$ and is denoted as $F_{3}^{r}$. Forces $F_{3}^{t}$ and $F_{3}^{r}$ counterbalance each other and in common are marked as $F_{3}$. There are three twin forces $F_{1}, F_{2}, F_{3}$ between supports $S 1, S 2$, S3 and assembled shaft at Fig. 3.

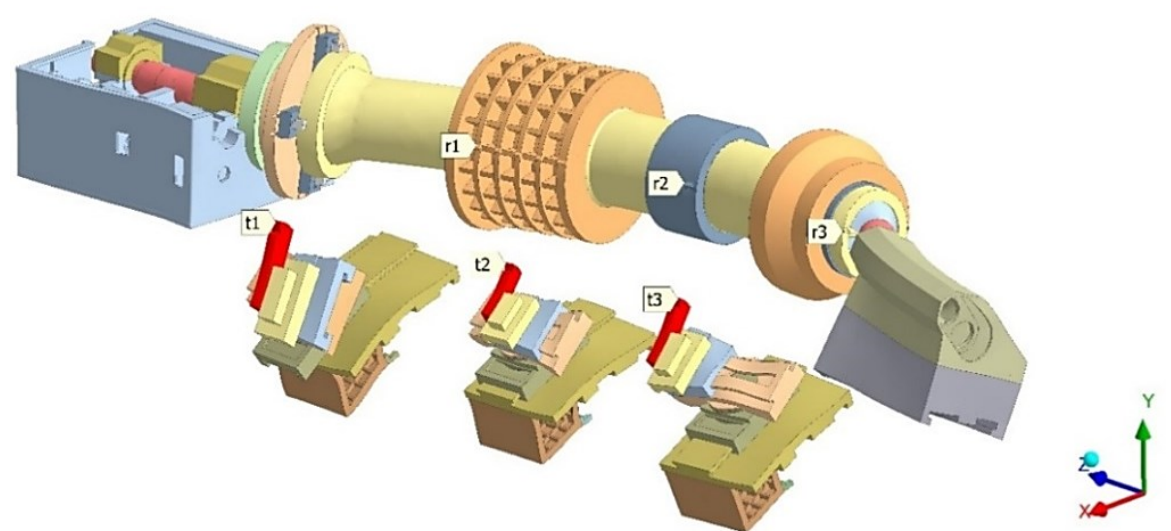

Fig. 3. Paired reference points «tool - shaft»: $t 1, t 2, t 3$ - at the tools upon supports; $r 1, r 2, r 3-$ at the opposite cutting zones on rotor, bearing and shaft butt (every pair of points disconnected by twin forces of $1 \mathrm{kN}$ each); $\times 300000$

Not only twin force test is provided. Fig. 4 shows variant of the lathe balanced static loading by five forces. Rotor shaft is absent. Three supports and both stocks are burdened in radial direction. It is necessary for structural parts stiffness revealing.

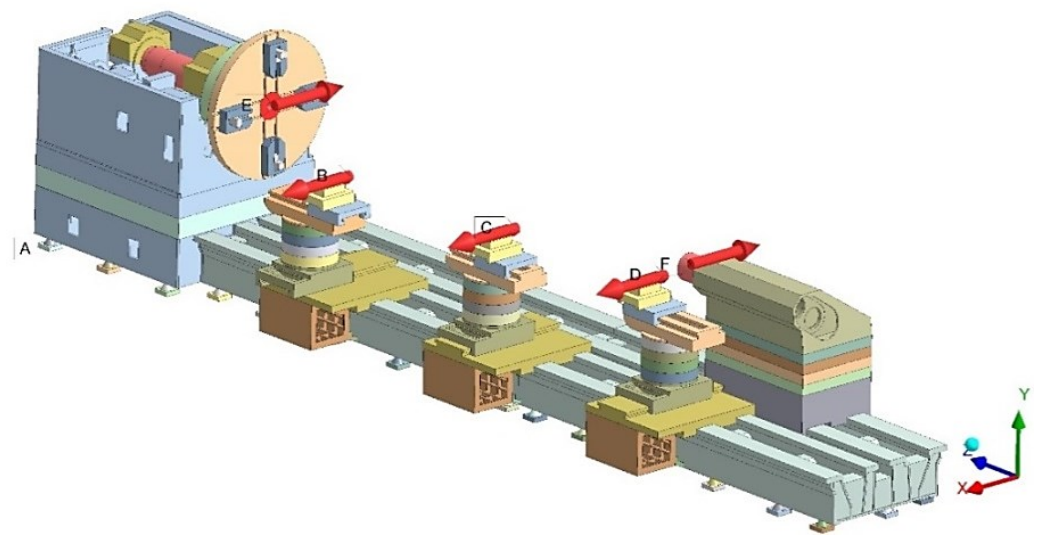

Fig. 4. Empty lathe balanced loading (foots fixation - $A)$ : forces $B, C, D(1 \mathrm{kN}$ each) on supports along $+X$; forces $E, F(1.5 \mathrm{kN}$ each $)$ - on chuck and quill along - $X$ 


\section{FEA-SIMULATION CONDITIONS}

Lathe before renovation are noted as $I H L$ (initial huge lathe - Fig. 3). Height of centerline rising $h$ is varied in present work in range from 0 to $600 \mathrm{~mm}$. Lathe with centerline rising at half-range $(h=$ $300 \mathrm{~mm}$ ) will be referred as $R H L$ (raised huge lathe - Fig. 1, 2). Lathe in $R H L$ state is minimal aim for renovation.

When centerline is rose at full range $(h=600 \mathrm{~mm}$ ), it will be EHL (elevated huge lathe - Fig. 4). That machine tool became too tall. It supports visually transform to "machining columns". Lathe rebuilding from $I H L$ to $E H L$ state isn't mandatory. $E H L$ model will be simulated onwards for full situation review.

RHL machine was described and simulated in case of centerless turning (Vasilevich and Dounar, 2017). Techniques that work are implied in the present investigation.

Simulation was provided with lunette mounted (feature WithL) so with no it presence (NoL). Mechanical bound between tools and shaft may be switched on (WithB) or off (NoB). It means engagement or disengagement between pairs of reference points $(t 1-r 1, t 2-r 2, t 3-r 3)$.

Static stiffness of any support $S_{i}$ is calculated as relation of force applied to tool vertex $\left(t_{i}\right)$ displacement along $X$

$$
J_{S_{i}}^{s t}=F_{i}^{t} / u_{i}^{t}, N / \mu m
$$

Radial rigidity of shaft in a cutting zone point $r_{j}$ is taken as

$$
J_{r_{j}}^{s t}=F_{j}^{r} / u_{j}^{r}, N / \mu m,
$$

where:

$u_{j}^{r}$ - deformational displacement of $r_{j}$ along $X$.

It is necessary to establish minimal allowable level of rigidity. Low dynamic rigidity provokes cutting autooscillations. It is recommended to retain it at resonance frequency above the level of $J_{\text {norm }}^{d}=20 \mathrm{~N} / \mu \mathrm{m}$ (Lopez de Lacalle and Lamikiz, 2008).

For static and nearby situations required rigidity should be tenfold higher than for dynamics $\left(U_{\text {norm }}^{s t}=200 \mathrm{~N} / \mu \mathrm{m}\right)$. This follows directly from standards for precise machine tools (Olvera et al., 2012). That norm concerns all reference points.

The system of finite element meshes was created. Volume meshes were joined by surface contact elements. Contact pairs had "bonded" status by default. Fixed attaching of real parts was simulated in such manner. Finite elements with 10 nodes dominated. Key highly loaded parts were meshed regularly with 20 -node elements.

Structural parts of lathe are made from cast iron. Steel is used for rotor, shaft, spindle, different plates, disks and stems. Elasticity modulus $E$, Poisson's ratio $\mu$ and specific gravity $\rho$ are taken for simulation accordingly tab. 1.

Forward and rear spindle bearings were both simulated as solid sleeves, without rolling bodies inside. Imaginary, model material $m 1$ was assigned to bearings for correct rigidity parameters. Elasticity modulus for $m 1$ was tuned during preliminary FEA tests with auxiliary models to correspond to bearing catalogue data. Foots under lathe bed were simulated as solid cones (model material $m 2$ ). Vertical stiffness of each foot is tuned at $3600 \mathrm{~N} / \mu \mathrm{m}$ and horizontal one - at $950 \mathrm{~N} / \mu \mathrm{m}$.

Table 1.

Mechanical properties of modelling materials

\begin{tabular}{|l|c|c|c|}
\hline \multicolumn{1}{|c|}{ Materials } & $\boldsymbol{E}, \mathbf{M P a}$ & $\boldsymbol{\rho}, \mathbf{k g} / \mathbf{m}^{\mathbf{3}}$ & $\boldsymbol{\mu}$ \\
\hline Cast iron & 130 & 7200 & 0.28 \\
\hline Steel & 200 & 7850 & 0.3 \\
\hline Concrete (generalized) & 30 & 2300 & 0.18 \\
\hline Spindle bearing material $m 1$ & 4 & 7850 & 0.3 \\
\hline Foot material $m 2$ & $25-35$ & 2000 & $0.15-0.22$ \\
\hline
\end{tabular}

Concrete (generalized, e.g. polymer concrete) properties were established at middle level in range (Brailovskij et al., 2010) of possible recipe variations. Rotation of rotor, shaft, chuck and spindle isn't simulated. Quill is fastened into tailstock. 


\section{PATTERN OF STATIC DEFORMATION AND RESONANCES}

Fig. 3 shows lathe deformations under all three twin force action. Simulation accomplished for $I H L$ without lunette $(\mathrm{NOL})$ and tool-shaft bond $(\mathrm{NoB})$. Opposite motion of tools and shaft is clearly visible. Shaft undergoes bending. Each support swings backward. Quiet similar pattern is revealed for "grown up" lathe (EHL) on Fig. 5. Only one twin force on support $S 2$ is applied $\left(\mathrm{F}_{2}^{\mathrm{r}}=\right.$ $-\mathrm{F}_{2}^{\mathrm{t}}=1 \mathrm{kN}$ ). Summary tool displacement reaches $5.67 \mu \mathrm{m}$. It doubly exceeds shaft maximal displacement $(2.78 \mu \mathrm{m})$. Hence just support is critical object as to stiffness during centerline rising. Flexibility of shaft would not be the issue.

Concrete pouring may be used to improve support stiffness (marker Conc here below). Simulation was provided with "bonded" status for contacts between iron bed and concrete inserts. Common growth of support rigidity was indicated (Table 2). Important to note existence of inner degrees of freedom, caused by several sliders and carriages stacked on support basement. That is why support differently hangs from guides depending on machining diameter. It scatters situation in Table 2.

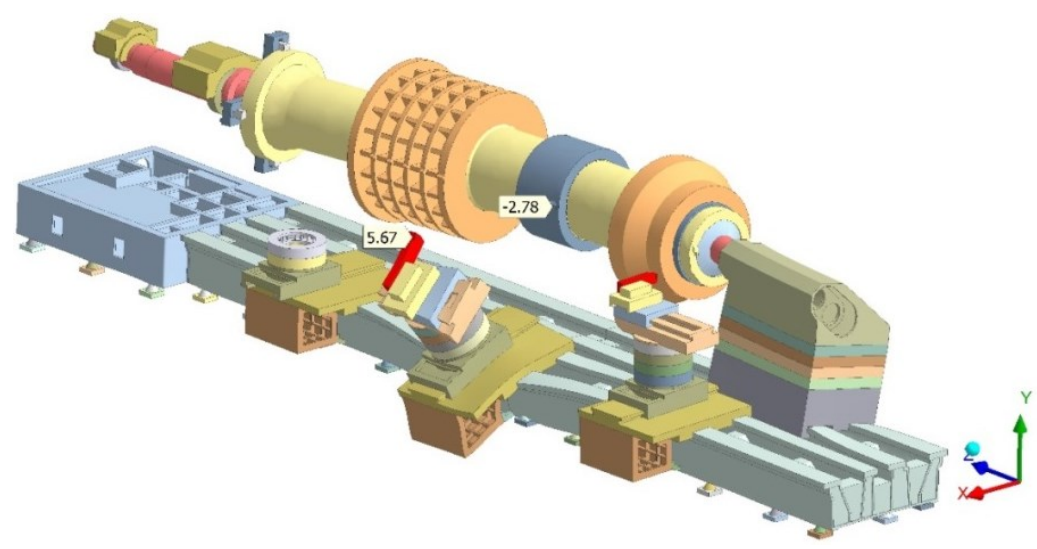

Fig. 5. Static opposite loading of shaft and support $S 2$ by twin force $F_{2}^{r}=-F_{2}^{t}=1 \mathrm{kN}: \mathrm{h}=600 \mathrm{~mm}$; NoL, NoB; displacements $(\mu \mathrm{m})$ in loading points; $\times 300000$

Table 2.

Stiffness increasing (times) of support after pouring concrete into bed

\begin{tabular}{|c|c|c|c|}
\hline \multirow{2}{*}{ Rising height $\boldsymbol{h}, \mathbf{m m}$} & \multicolumn{3}{|c|}{ Support } \\
\cline { 2 - 4 } & $\mathbf{S 1}$ & $\boldsymbol{S 2}$ & $\mathbf{S 3}$ \\
\hline 0 & 1.31 & 1.42 & 1.61 \\
\hline 300 & 1.39 & 1.69 & 1.35 \\
\hline 600 & 1.31 & 1.41 & 1.57 \\
\hline
\end{tabular}

Main effect from concrete filling - static rigidity increasing in 1.45 times averagely for just supports. Shaft rigidity growth is slight ( $11 \%$ only). So concrete pouring is a measure to improve rigidity of guideways and above placed parts.

Shape of main (lowest) shaft resonance MR1 is showed at Fig. 1, a. It frequency holds in range $13.27-18.24 \mathrm{~Hz}$ for any variations of rising height $\mathrm{h}$ and other parameters. Shaft is bending in half-wave shape with two nodes placed on the centerline inside headstock and tailstock. Spindle unit and quill oscillate. Antinode lays between rotor $R t$ and radial bearing $R b$.

Natural frequency of $M R 1$ is rather stable for parameter variations. During $C R P$ frequency $\mathrm{f}_{\mathrm{MR} 1}$ decreases from 15.0 to $13.27 \mathrm{~Hz}$ (on $11.5 \%$ only). For $R H L$ case such strong measure as lunette mounting was simulated. It has lead to moderate $25 \%$ enhancement of $f_{M R 1}$ (from 14.58 to 18.24 $\mathrm{Hz})$.

Main resonance of any support consist in its swinging in radial direction (Fig. 2 - support S2), what is dangerous for lathe precision. Resonance frequencies of all three supports differ from each other slightly depending on inner coordinates of that one. Support resonances fall in range $42.7-70.0 \mathrm{~Hz}$ for any parameter variations.

Main resonances of supports are signed as MS1a, MS1b, MS1c for S1, S2, S3 relatively. Centerline rising decrease MS1a frequency from 55.4 to 42.7 only (22.9\% lowering for $I H L-E H L$ 
transition). It shows robustness of main eigenmodes. Renovation with CRP looks like appropriate at least for level $h=300 \mathrm{~mm}$.

It should be noticed, that main shaft resonance MR1 occur at thirdly lower frequency than supports main resonances MS1a, MS1b, MS1c. Hence, rotor shaft needs priority attention in dynamics sense during $\mathrm{CRH}$.

\section{DISCUSION ABOUT RIGIDITY CHANGES CAUSED BY CENTERLINE RISING}

Fig. 6 illustrates uniform slow lowering of shaft rigidity during centerline rising. Curves relate to three load cases, where the same twin force is applied to paired points $t 1-r 1$, then $t 2-r 2$ and then t3-r3. Lathe is in state NoL, NoB.

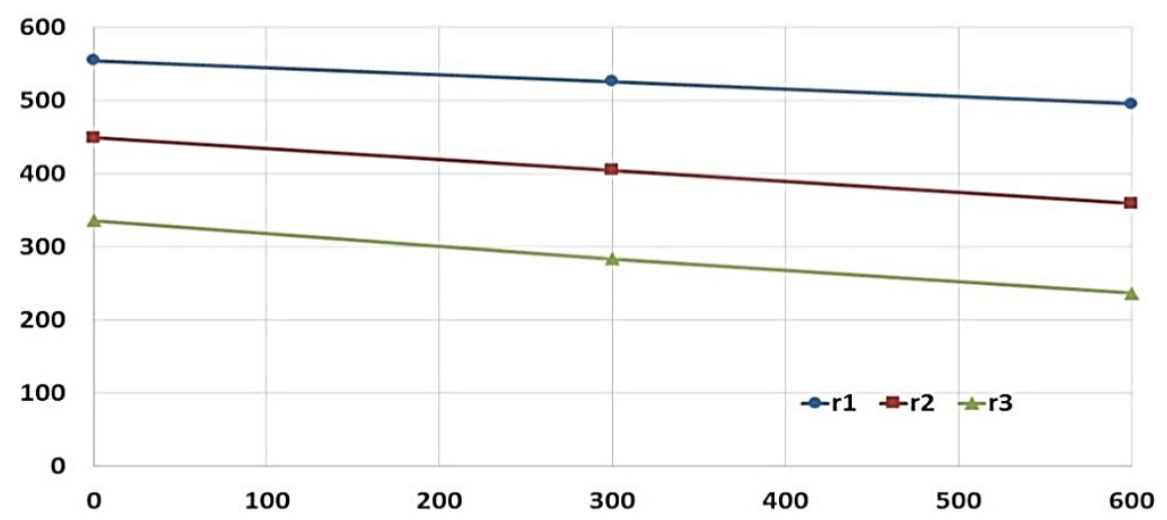

Fig. 6. Static radial rigidity of shaft $J_{r_{j}}^{s t}$ in the points $r 1, r 2, r 3$ depending on rising height $h, \mathrm{~mm}$.

Even in case of lunette absence, shaft rigidity is HELD above minimal allowable level $\left(U_{\text {norm }}^{\text {st }}=200\right.$ $\mathrm{N} / \mu \mathrm{m}$ ). Rigidity decreasing is relatively small (no more $25 \%$ during $C R P$ ) in the forward and middle shaft parts. All curves have weak slope. Rear part of shaft (near tailstock) is the most flexible one. Its pliability increases in 1.41 times by $I H L-E H L$ transition. Thereby shaft backing should be provided by tailstock and nearby placed lunette at the same time.

Will discuss influence of centerline rising on headstock and tailstock rigidity. Loading was provided accordingly to Fig. 4. Flexibility of spindle unit and quill unit were taken into account. Results are showed in the Table 3. Percent data in brackets means part of initial rigidity remaining during $C R P$.

Table 3.

Radial rigidity of headstock and tailstock (lathe without shaft) depending on rising height $h$

\begin{tabular}{|c|c|c|c|c|}
\hline \multirow{2}{*}{$\#$} & \multirow{2}{*}{ Radial rigidity, N/um } & \multicolumn{3}{|c|}{ Rising height $\boldsymbol{h}, \mathbf{m m}$} \\
\cline { 3 - 5 } & & $\mathbf{0}(\mathrm{IHL})$ & $\mathbf{3 0 0}(\mathrm{RHL})$ & $\mathbf{6 0 0}(\mathrm{EHL})$ \\
\hline 1 & Headstock HS, $J_{H S}^{s t}$ & 645.2 & $580.9(90 \%)$ & $548.0(84 \%)$ \\
\hline 2 & Tailstock TS, $J_{T S}^{s t}$ & 286.3 & $241.7(84 \%)$ & $202.4(71 \%)$ \\
\hline 3 & HS to TS ratio $k_{J}=J_{H S}^{s t} / J_{T S}^{s t}$ & 2.25 & 2.40 & 2.71 \\
\hline
\end{tabular}

Headstock rigidity is sufficient for statics and averagely threefold exceeds minimal allowable level. Tailstock is more flexible ( 2.5 times) comparing to headstock. It is appropriate to redesign tailstock and extent its basis upon guides.

Positive feature of both stocks is moderate interaction with centerline rising. Table 3 shows at least $70 \%$ residual of rigidity after transition from $I H L$ to $E H L$. It means natural lathe robustness.

Data in Table 4 concerns to radial stiffness of supports during CRP. Pattern is near the same for all three supports. Each step $(300 \mathrm{~mm})$ in centerline rising decreases stiffness in 1.4 times approximately.

Radial stiffness of support depends on machining diameter. Bigger diameters rely to lesser stiffness. Inner coordinates influence is clearly showed for support S3. Tool is shifted far away from support center and too much hangs out. Therefore, stiffness for S3 is lower than for S2 despite of lesser machining diameter. Rotor shaft is held at the ends by headstock and tailstock. 
Table 4.

Supports radial stiffness $(\mathrm{N} / \mu \mathrm{m})$ depending on centerline rising (in brackets - ratio "support stiffness/shaft rigidity" in paired points $t_{i}-r_{i}$ )

\begin{tabular}{|c|c|c|c|c|c|c|}
\hline \multirow{2}{*}{$\begin{array}{c}\text { Support } \\
\text { and point }\end{array}$} & \multirow{2}{*}{ Diameter } & \multicolumn{3}{|c|}{ Stiffness $\boldsymbol{J}_{\boldsymbol{S}_{i}}^{\text {st }}$ depending on $\boldsymbol{h}$} & \multicolumn{2}{c|}{ Stiffness lowering } \\
\cline { 3 - 7 } & & $\mathbf{0}$ & $\mathbf{3 0 0}$ & $\mathbf{6 0 0}$ & $\mathrm{RHL}$ & $\mathrm{EHL}$ \\
\hline$S 1, t 1$ & $\varnothing 2090$ & $209.0(37 \%)$ & $151.0(28 \%)$ & $112.4(22 \%)$ & 1.38 & 1.86 \\
\hline$S 2, t 2$ & $\varnothing 1420$ & $329.2(73 \%)$ & $238.3(58 \%)$ & $176.2(49 \%)$ & 1.38 & 1.87 \\
\hline$S 3, t 3$ & $\varnothing 1074$ & $296.3(88 \%)$ & $211.3(74 \%)$ & $156.6(66) \%)$ & 1.4 & 1.89 \\
\hline
\end{tabular}

Usefulness of optional intermittent holder - lunette $L$ - was studied out by simulation for statics (Table 5).

Table 5.

Shaft radial rigidity increasing caused by lunette mounting (RHL; $h=300 \mathrm{~mm}$ )

\begin{tabular}{|c|c|c|c|}
\hline \multirow{2}{*}{$\begin{array}{c}\text { Points } j \text { on the } \\
\text { shaft }\end{array}$} & \multicolumn{2}{|c|}{ Shaft rigidity $J_{r_{j}}^{s t}, \mathbf{N} / \mu m$} & Rigidity increase, \\
\cline { 2 - 3 } & Lunette absent - NoL & Lunette mounted -WithL & 1.32 \\
\hline$r 1$ & 526.1 & 692.2 & 1.67 \\
\hline$r 2$ & 404.7 & 676.1 & 1.37 \\
\hline$r 3$ & 283.7 & 387.6 & 1.50 \\
\hline Average & 404.8 & 585.3 & \\
\hline
\end{tabular}

Lunette substantially increases shaft rigidity - one and half time average. Lunette reinforces shaft near $r 2$ reference point much more than in vicinity of $r 3$ point. However, axial coordinate $Z$ for lunette placing is hardly varied. Lunette may be mounted only in not numerous slots between parts assembled on shaft.

\section{CONCLUSIONS}

1. Static rigidity in the rotor shaft machining points weakly depends on the centerline rising procedure $(C R P)$. Spindle rigidity decreases on $15 \%$ only (to $548 \mathrm{~N} / \mu \mathrm{m}$ ) during $C R P$ at 600 $\mathrm{mm}$. Stiffness of tailstock lowers in 1.42 times (to $202 \mathrm{~N} / \mu \mathrm{m}$ ). Reinforcement is desirable for tailstock only.

2. Each of three supports is more flexible then opposite machining point on the shaft. Difference grows as centerline going to rise. Support near headstock is $\sim 4$ times more pliable compared to shaft and support near tailstock - in $\sim 1.5$ times.

3. Centerline rising at $300 \mathrm{~mm}(R H L)$ is allowable for current lathe design. Concrete filling is advised. That measure increases supports static stiffness on $45 \%$.

4. Centerline rising at $600 \mathrm{~mm}(E H L)$ is admissible only after tailstock and supports redesign. Concrete filled bed is also needed. EHL would be effective for rotor machining with slow rotation of shaft and fast spinning of tool (end mill e.g.).

5. Main (lowest) resonance MR1 of shaft assembly is a half-wave bending. It embraces as shaft itself so headstock and tailstock. Eigenmode $M R 1$ is very stable against centerline rising and other parameters variations. CRP from 0 to $600 \mathrm{~mm}$ has decreased modal frequency from 15.0 to $13.27 \mathrm{~Hz}$ only.

6. Main resonances of all three supports (MS1a, MS1b, MS1c) show radial swinging. Centerline rising from 0 to $600 \mathrm{~mm}$ reduces eigenmode frequencies moderately (for from 55.4 to 42.7 $\mathrm{Hz}$ ). It shows robustness of lathe main eigenmodes. According to all points of view, lathe renovation is allowable with centerline rising on $300 \mathrm{~mm}$ at least.

\section{REFERENCES}

Brailovskij, M.I., Voskobojnik, A.G. and Voskobojnik, A.A. (2010). Metal-concrete systems for metal-cutting machines. Russ. Fed.: Kolomna, Voentechizdat.

Cao, Yan; Chen, Hue; and Zhao, Haixia. (2011). Turning process modelling and cutting force investigation based on finite element analysis and cutting experiments. In: International conference on advanced design and manufacturing engineering. Peoples R. China: Guangzhou. Advanced material research. Volume 314-316, parts 1-3, p.900-903. 
Haddag, B., Nouari, M. and Moufki, A. (2016). Some cases of machining large-scale parts: characterization and modelling of heavy turning, deep drilling and broaching. In: Proceedings of the $19^{\text {th }}$ International ESAFORM Conference on material forming. France: Nantes. AIP Conference proceedings, Volume 1769, Article number 080004, Apr 27-29, 2016.

Lopez de Lacalle, L.N., Lamikiz, A. (2008). Machine Tools for High Performance Machining. London: Springer-Verlag.

Olvera, D., Lopez de Lacalle, L.N., Compean, F.I., et al. (2012). Analysis of tool tip radial stiffness of turn-milling centers. International Journal of Advanced Manufacturing Technologies, 60(912), p.883-891.

Simon, M., Grama, A L., Ganea, M. (2012). Study of improving static rigidity on machine tool structure using concrete component. The 6th edition of the Interdisciplinarity in Engineering International Conf. "Petru Maior" University of Tîrgu Mureş, Romania, 26-29.

Vasilevich, Yu. V., Dounar S.S. and Karabaniuk I.A. (2016). Finite element analysis of filler influence on dynamic rigidity of heavy machine tool portal. Science \& Technique, 15(3): 233241.

Vasilevich, Y.V., Dounar, S.S. (2017). Finite element analysis of centerless-lunette turning of heavy shaft. Science \& Technique.; 16(3): 196-205.

Wu, Dongxu; Wang, Bo; Luo, Xichun; et al. (2015). Design and analysis of aerostatic spindle with high load characteristics for large ultra-precision drum lathe. Proceeding of the institution of mechanical engineers. Part J. Journal of engineering tribology. Volume 229(12), 1425-1434.

Zienkiewicz, O.C. and Taylor, R.L., (2000). The finite element method. Vol.1. Basis. Oxford: Butterworth-Heinemann. 